\title{
THUNDERBOLTS: THE ELECTRIC PHENOMENA OF THUNDERSTORMS
}

\begin{abstract}
A GEOPHYSICAL Discussion at the Royal Astronomical Society, held on January 25, was devoted to the subject of thunderbolts. The choice of date was, unintentionally, felicitous because, as the Secretary of the Society mentioned, January 25 is the recognized anniversary of the turning point in the life of St. Paul, when "suddenly there shined round about him a light from heaven; And he fell to the earth...", blinded by the shock.

In introductory remarks, Mr. E. Gold (chairman) said that, in ancient and classical times, the word translated thunderbolt was generally used for ordinary lightning discharge, "begotten from thick clouds piled on high". A reference in Abelard's letter to a friend-" "the high summits call the thunderbolt" -implies that also in medieval times the thunderbolt was ordinary lightning. But nowadays the word thunderbolt often implies an unusual phenomenon such as ball lightning. The discussion, he said, would be concerned mainly with the fundamental physics of thunderstorms. A knowledge of the fundamental physics, in which many advances have been made in recent years, is essential not only for the understanding of ordinary lightning but also for the elucidation of certain electrical phenomena of thunderstorms which, according to the evidence of credible witnesses, were neither ordinary lightning nor imaginary apparitions.
\end{abstract}

Dr. T. W. Wormell spoke of the light thrown by recent investigations at Cambridge on the mechanism of the lightning discharge and on the processes causing the electrification of the clouds. Records at Cambridge of the electric field near the earth's surface during lightning flashes at distances between $20 \mathrm{~km}$. and $100 \mathrm{~km}$. show that in much earlier work the importance of the slower parts of the discharge has not been adequately appreciated. In these recent records special care has been taken to ensure that quite slow variations of the field are faithfully delineated, and this has furnished direct information of the vertical movement of the electric charge during a discharge. In a typical change of field, the slow variation lasts for $0.3 \mathrm{sec}$. or more; but it is interrupted in some cases by much more rapid changes with a duration of the order of 0.001 sec. The slow variation is sometimes intermittent, as in the luminous steps photographed by Schonland and his colleagues, but the phenomenon is comparatively rare in the Cambridge records and is usually confined to quite brief portions of the slow change of field.

The presence on the record of major rapid portions of the field-change indicates a discharge to earth. An analysis of 1,500 discharges shows that 37 per cent of all flashes reached the earth, 32 per cent bringing down negative charge only, 3 per cent positive charge only and 2 per cent charges of both signs. The other predominant type of discharge, 45 per cent of all flashes, is within the cloud and takes negative charge upwards.

The initial slow variation of field on the occasions of discharge of negative electricity to earth has a mean duration of the order of 0.1 sec., a figure greatly in excess of previous estimates. Slow varia tions may occur between the subsequent rapid variations; but in about three-quarters of the examples these slow variations are very slight, implying that the regions successively discharged to earth were all at about the same height. In the remaining examples, the records of change of field indicate that the heights of the regions discharged increase at successive steps.

Schonland in 1938 suggested that successive discharges originated in neighbouring 'cells' in the cloud, all with approximately the same base-level, a conception fitting three-quarters of the Cambridge records. But this conception of separate cells was abandoned by Schonland in 1951, because an examination by him and Malan of the field-changes in South African storms showed that, in these storms, successive strokes normally came from regions "which are progressively higher and higher within the cloud".

This difference in predominant character between the storms in England and those in the plateau region of South Africa emphasizes the need for similar investigations elsewhere, especially in equatorial sea-level areas and in high-level plateau regions of the temperate zone.

The normal negative potential gradient beneath a thundercloud is often interrupted by periods of positive gradient, usually associated with very heavy rain. Mr. I. C. Browne, at Cambridge, using a radar vertical beam, wave-length $3 \mathrm{~cm}$, finds intense echoes from quite a low height on such occasions, and the intensity increases steeply with decreasing height. These observations appear to support the Simpson-Scrase explanation of the positive charge in the base of thunderclouds as due to the breaking of drops in an ascending current. But there are difficulties in reconciling this interpretation of the radar results with the observed rate of rainfall. Further, the process appears inadequate to produce a large enough positive charge.

Dr. F. J. Scrase spoke of the distribution and generation of electricity in the cloud and of the essential differences in electric character between the shower-cloud and the thunderstorm-cloud. The first direct information about the distribution of electricity in the thundercloud was obtained just before the Second World War by balloon soundings inside the clouds at Kew. These showed a bi-polar structure, with positive electricity in the upper half of the cloud and negative in the lower half. They also disclosed the unexpected existence of a pocket of positive charge embedded in the lower part of the negative half of the cloud. This was so surprising that there were, not unnaturally, doubts about its reality. These doubts have now been resolved. The existence of this positive charge has been confirmed by aircraft observations in cloud in the United States and by observations in cloud on the summit of the Zugspitz $(10,000 \mathrm{ft}$.$) in Europe. It seems now practically$ certain that this pocket of positive charge in the base of the cloud is essential for the initiation of a discharge. This requires a very strong electric field, and these two closely placed positive and negative charges can, as pointed out by Whipple in 1938, produce the necessary intense local fields. The soundings at Kew indicated that the intense fields did occur only in limited regions, because fields exceeding $100 \mathrm{~V} . / \mathrm{cm}$. were found in only 15 per cent 
of the soundings. There could not, therefore, have been large horizontal sheets of positive and negative electricity with intervening fields approaching the discharge value of $10,000 \mathrm{~V} / \mathrm{cm}$. as a general feature of thunderclouds. Ross Gunn, from aircraft measurements, found average maximum fields about 1,300 $\mathrm{V} . / \mathrm{cm}$. (highest value $3,000 \mathrm{~V} . / \mathrm{cm}$.), and considers that such high fields are more widespread than the Kew soundings indicate. Although the Kew apparatus showed whether the field was less or greater than $100 \mathrm{~V} . / \mathrm{cm}$., it was not designed to record the actual value of the field, and the maximum values on those occasions when the apparatus showed a field greater than $100 \mathrm{~V} \cdot / \mathrm{cm}$. may well have been $1,000 \mathrm{~V} . / \mathrm{cm}$. or even the discharge value of 10,000 V. $/ \mathrm{cm}$.

The electrical structure of the shower-cloud is similar to that of the thunder-cloud, but the showercloud does not usually have the positive charge in the base; and the vertical extent of the negative charge is substantially smaller. At Kew the negative charge extended from the base at $1.5 \mathrm{~km}$. up to $3 \mathrm{~km}$. for showers, up to $4.5 \mathrm{~km}$. for moderate thunderstorms and up to $7.5 \mathrm{~km}$. for violent thunderstorms, with a maximum of $9.5 \mathrm{~km}$. Schonland and Malan estimated that in South African storms the negative region extended from $3.5 \mathrm{~km}$. (above sealevel) up to levels between $4.5 \mathrm{~km}$. and $10 \mathrm{~km}$. according to the violence of the storm. Radar investigations support these conclusions. They indicate that the vertical columns giving radar echoes are greater (in height) for thunderstorms than for showers, and the echoes are much more intense from thunderstorms. 'The 'radar cloud' of thunderstorms usually reaches a height at which the temperature is below $-40^{\circ} \mathrm{C}$. The 'radar eloud' of showers may reach only to $-10^{\circ} \mathrm{C}$. and practically never reaches beyond $-30^{\circ} \mathrm{C}$.

The generation of the main charges in the thundercloud, and probably also in the shower-cloud, appears to depend on the presence of ice crystals. It may bo brought about by impact, as suggested by Simpson, or it may be due to splintering, now known to occur, during the rapid growth of the crystals by accretion. The vertical separation of the charges is due to gravity. Either the negative charge is on ice particles or drops, and the positive charge on ions, or the negative charge is on large ice crystals and the positive charge on small fragments of ice crystals. In both cases the negative charge is carried downwards by gravity and the positive charge left in the upper part of the cloud.

The generation of the pocket of positive charge in the base is probably due to the breaking of large water drops. The charge is practically always found in a region where the temperature is above freezing point. In fact, one of the differences between the showers and thunderstorms investigated at $\mathrm{Kew}$ is that the latter have their bases well below the freezing level and therefore at a temperature well above freezing point. Aircraft and radar observations indicate that the necessary accumulation of large drops in the lower part of the cloud is initiated by the strong updraughts which carry a copious supply of water to high levels.

Schonland has suggested an alternative method of generation of this lower positive charge on lines indicated tentatively by Whipple in 1938. If upwardmoving positive ions due to point-discharge from the ground attach themselves to water drops in the base of the cloud, their electrical mobility disappears and they become concentrated into a pocket of positive charge in the cloud.

Dr. R. H. Golde dealt with the question of so-called 'lightning nests'-regions with an excessive concentration of lightning discharges. The published evidence for these, he said, does not appear sufficient to satisfy rigorous statistical examination; but it has been suggested that underground watercourses or geological faults or unusual conductivity of the air over a region might produce such 'nests'. Dr. Golde has examined theoretically the possible effects of the ground on concentration of lightning. The height of the advancing tip of a downward-moving leader stroke at which complete breakdown of the remaining air space can be expected to occur in the form of an upward streamer from the ground to this advancing tip is about 15 metres for a stroke of average intensity and 100 metres for a stroke of maximum intensity. Field observations confirm that these theoretical values are of the right order of magnitude. It is therefore only at these comparatively small heights that the point ultimately to be struck is determined. A buried cable or a lightning conductor $10 \mathrm{~m}$. high may attract lightning strokes over distances, increasing with the intensity of the stroke, but less, for the cable, than 100 metres and, for the lightning conductor, than 200 metres. A narrow geological fault or an underground water-course, surrounded by soil of high resistivity, can be expected to be intermediate between these two in its effects on the electrostatic field. They may thus cause narrowly localized 'concentrations' of lightning discharges ; but a concentration over larger areas can only be explained by topographical features or by properties of the atmosphere over these areas and not by features below the earth's surface. On the average in England, the estimated number of flashes to a strip $200 \mathrm{~m}$. wide and $1 \mathrm{~km}$. long is less than c ne in two years; to a circle of $100 \mathrm{~m}$. radius it is less than one in ten years. Dr. Tromp, of Leyden, convinced that lightning flashes do tend to be concentrated in zones of high conductivity gradients at the earth's surface, has suggested a systematic study of the geology and soil conductivity at points struck by lightning over a number of years.

In reply to a query, Dr. Golde said that magnetization of basaltic rocks is caused not infrequently by lightning; and this phenomenon has, in fact, led to the development of magnetic devices for indicating the magnitude of the currents in lightning flashes to earth.

Dr. E. T. Pierce gave a brief account of investigations into the field changes to be expected from negatively charged leaders starting from the base of the thundercloud, advancing with speeds of $10^{5}-10^{8}$ $\mathrm{cm}$./sec. and carrying currents of the order of 100 amp. In such leaders arc conditions exist, and corona currents develop. He has derived curves for the change of field with time during leader stages, using

a formula for the corona current, $I_{c}=k\left[\int_{0}^{l} x d l\right]^{2}$,

more general than that of Bruce in that $x$, the general field-strength, is not assumed constant but is a function of $l$, the length of the leader from its origin. The curves derived are in good agreement with those actually recorded at Cambridge. The value of the corona constant $k$ comes out at $10^{-16}$ M.K.S. units, a value consistent with McEachron's observations on the Empire State Building, New York. If the general field, $x$, increases slowly upwards, the leader field- 
change approximates to the $\alpha$-type-leaders of uniform velocity $2 \times 10^{7} \mathrm{~cm}$. $/ \mathrm{sec}$. As the increase of general field with height becomes more rapid, the leader field-change approaches more closely the $\beta$-type-leaders moving during the first part of their track at a much higher velocity, $1.5 \times 10^{8} \mathrm{~cm} . / \mathrm{sec}$.

Mr. J. Durward, deputy director, Meteorological Office, contributed two observations of unusual phenomena. In the summer of 1934 he was motoring along the south bank of Loch Tummel. It began to rain heavily, with slight or moderate thunder and lightning. His son, a boy of twelve, was opening the iron gates, spaced at regular intervals on this road, and found one difficult to open. Mr. Durward, while walking the short distance from the motor-car to the gate to assist his son, saw among the pine trees on his left what looked like a ball of fire about 12 in. in diameter moving towards them. It struck the iron gate-post farthest from the latch. There was no noise, but the boy, who had his hand on the latch, gave a yell; for the next few hours he was unable to lower his arm. The second incident was in the late summer of 1938 en route for Iraq in a B.O.A.C. flying-boat. Just after passing the Toulouse gap, in dense nimbostratus cloud at a height of $8,500 \mathrm{ft}$., what appeared to be a ball of fire entered the rear cabin and burst with a loud explosion. The captain of the aircraft told Mr. Durward about one to two minutes after the explosion that he had had the cockpit window open, for visibility, that the ball of fire entered by the open window, burned off his eyebrows, some of his hair, a hole in his safety belt and dispatch case. From the cockpit the ball passed through the dispatch clerk's 'office' and the forward passenger cabin without harming anybody or anything-only in the rear cabin was there an explosion. About the same time as the aircraft was struck, the hotel at Marseilles, where the passengers were to spend the night, was struck by a 'coup de foudre' and burned out. Mr. J. F. Shipley said that fifty years ago on a hot oppressive afternoon he had seen from the top of an omnibus in the Fulham Road, London, 'ball lightning' apparently about 6 in. in diameter and 15 yds. away, floating in the air. As he watched it, he saw a flash of lightning and the ball disappeared. There was no noise.

These and other observations, notably some of those related by F. Sauter in the Meteorologische Zeitschrift of July 1895, by W. J. Humphreys in the Proceedings of the American Philosophical Society of 1936, and by W. Brand in "Der Kugelblitz" (reviewed in Nature, 113,677 ; 1924) dispose of the contention that ball lightning is not a real physical phenomenon but an optical illusion-an after-effect of the flash of ordinary lightning or St. Elmo's fire. Not only is ball lightning a physical phenomenon, but also there are two distinct kinds-the noiseless and the explosive type.

The most likely source of ball lightning is that originally suggested by Dr. T. E. Allibone and repeated in the discussion, namely, the junction of the tip of the downward moving negatively charged stepped leader with the end of the upward positive streamer from earth. Th. Neugebauer showed that a concentrated ball of negative electrons and positive ions is stable up to high temperatures, the limiting temperature increasing with increasing electron density. The ball could persist for some time owing to the diminished rate of recombination of electrons and ions at high temperatures. If the original electron density and temperature are relatively low, the ball simply decreases in size, at the same time increasing in density and therefore in stability, and finally disappears silently owing to cooling by radiation. If, however, the original electron density and temperature are high, the electron density may diminish rapidly enough for the critical temperature for stability to fall below the actual temperature of the ball, which then explodes. The electron density must be very high, nearly $10^{20}$ electrons per c.c., to ensure stability at the temperatures of a luminous ball. Such densities are possible at the tip of a lightning stroke; but they are beyond the range so far achieved in the laboratory. Even in the lightning stroke, away from the tip, the maximum estimated density is only of the order $10^{15}-10^{16}$ per c.c. The comparative rarity of ball lightning is therefore not surprising.

F. GOLD

\section{PROGRESS IN COLOUR TELEVISION}

\section{By DR. R. L. SMITH-ROSE}

A LI'HOUGH the public television service started in Great Britain before the Second World War, the active development of a scheme for giving almost nation-wide coverage to this service has taken practical shape during the past five years. In the United States, television as a direct practical application of some of the electronic techniques developed during the War years caught the public imagination to such an extent that the television industry there, starting from almost nothing a few years ago, is now claimed to be one of the most widespread and active industries in the country. With its 107 television transmitting stations operating in the United States and more than thirteen million receiving sets each containing a cathode-ray tube for the display of the received picture, it is interesting to recall that the suggestion for using beams of electrons for this purpose was first made by $A$. A. Campbell Swinton in a letter published in Nature in $1908^{1}$. It was clear even at that date that, for the successful transmission of pictures to a distance, these pictures must be reproduced at least ten times a second, and that the electrical signals carrying the picture information would be subject to variations of about 160,000 times a second.

\section{Television and Radio Spectrum Band-width}

From these elementary considerations have beën built up the various television systems in use to-day, which present the pictures at a repetition-rate of $\mathbf{2 5}$ a second in Europe, and 30 a second in the United States. The quality of reproduction may be partly specified by the number of lines in which the picture is scanned; and for the four main systems of transmission which have received attention at international conferences in recent years, the numbers of lines used are 405 (Great Britain), 525 (United States), 625 (Netherlands) and 819 (France). The detailed quality of the picture only increases with the number of lines if the frequency channel used for the transmission of the signals is adequate. Thus for the four systems referred to above, the ideal transmission characteristics require bands of width 5, 6, 7 and $14 \mathrm{Mc}$./s. respectively ${ }^{2}$. When it is realized that the total frequency band used for the television service in 